\title{
Factor Analysis on Internet Hot Concept Being Popular in China
}

\author{
Yan-ni Yang, An-ling Xiang, Ya-ling Yang, and Yi-rong Liu \\ School of Information Management, Wuhan University, Hubei Province, China
}

\begin{abstract}
Internet hot concept being popular often demonstrates the leading edge of the industry and improves the added value of products. In order to explore the main reason for these concepts being given a lot of attention in a short time, from memes perspective and based on the analysis of searching frequency, hot academic topics and attention of public opinion, we explored the important influencing factors of this phenomenon. The results showed that the main factors that influence the Internet hot concept being popular include the national policy, laws and regulations, the application of technology and evolution of business models, personalized needs of information on the internet and so forth.

Index Terms - Internet, hot concept, Internet memes, influencing factors.
\end{abstract}

\section{Introduction}

The communication and application of concept can bring hidden profits for the industrial development, especially for the Internet industry. Hot concepts always arouse more industry speculation than the research and discussion in the academia. It has been the stock-in-trade of Internet companies to demonstrate the leading edge of the industry and improving the added value of products through conceptual packaging. No matter it is the original Chinese concepts including 'Internet thinking', 'Internet finance' or foreign concepts such as 'big data', 'hybrid cloud'; no matter it is pure concepts including 'fans economy', 'data science' or technical product concepts such as 'virtual currency', 'wearable devices', from pure technology hype to business model, these concepts become popular among the cooperative applications of the Internet companies, which further benefits the industry as a whole. Taking the concepts of E-commerce, Internet finance, smart city, big data, wearable devices, and social network, for example, this paper explores and analyzes the reasons for these concepts being popular and their development process through the data collection and analyzing the high spot of search data.

\section{Literature Review}

Being an instant hit on Internet is often called Internet memes. Meme is a unit of cultural evolution, which realize interpersonal communication through copy or imitation. [1] Compared to traditional media, Internet has more technical capacity to achieve globalized spread of memes.[1] Internet memes is a high-profile phenomenon often referring to a certain kind of behavior, concepts, and popular words that spread quickly on the Internet so as to draw public attention. [2] It exists in the form of pictures, videos, and spreads among network users through blogs, social networking and so on. [3]
In the development of the Internet, it generated a large amount of science and technology as well as application services, which promote industrial upgrading and change people's social life and attitudes. In the process, they triggered people's imagination and spawned numerous Internet concepts. The research in academia about Internet hot concepts mainly includes the origin of the concept, the development of the concept, the technology and application involved in the concept and so on. Seen from the origin of the concept, IBM first put forward the idea about Smart Planet and then derived the concept of Smart City. Gu and his coresearchers (2013) pointed out, following the development pace of smart city in EU, South Korea, Japan, Germany and other countries and regions, it boosts a wave of constructing smart city in China and makes the concept of Smart City draw attention from all walks of life at the same time. [4] Why do the integration of the Internet of Things and the Social Network cause high-profile attention? Atzori (2012) thought the main reason is that people realize the social Internet of Things has much enlightenment for the future world where smart things are ubiquitous in our daily life. [5] Agrawal (2012) put forward that a variety of social information channels and unstructured information content make the explosive growth of data, so as to enhance the discussion extent of the concept of Big Data. [6] Meng (2013) maintained, setting the columns of Big Data and spreading the concept of Big Data in Nature, Science and other academic journals make it popular rapidly. [7]

Seen form the development of the concept, Uskela proposed in 2003 that due to the development supplier data interface, technology availability and the demand of backward compatibility of $2 \mathrm{G}$ network architecture, $3 \mathrm{G}$ network gradually formed its conceptual framework. [8] Bari (2013) considered that the specific application and technology are important factors in the innovative development of the Internet of Things whose concept development is driven by the relevant application. The advances in technology extend the scope of the development of Internet concepts, which connect the whole world in a low-cost and widespread way. [9] Seen from the technology and application involved in the concept, Qiu (2013) indicated that the rise of innovative Internet financial model products turn the concept of Internet finance into the hot topic of the industry. [10] Xie (2012) deemed that the mature employment of mobile payment, social network, cloud computing and other Internet technology promote the concept development of the Internet finance. [11] 
Based on the trend of Google search, the extent of Baidu search (one of the top Internet portal companies in China), the discussion extent of Sina microblog (the largest microblogging provider in China), the focus of academic research and combined with the analysis of text content and data, this thesis analyzes and explores the important influencing factors of the internet hot concepts rise and being popular.

\section{The Influencing Factors of the Concept Being Popular}

Since the Internet bubble, search engines, E-commerce and social applications become the important fulcrum of data economic in PC Internet era. At the same time, the innovation of mobile technology industry attributes to the blasting development of mobile payment, news client and other mobile applications. The Internet of Things changes people's lifestyle and pushes the development of information industry to a new level. According to the search trend and extent of Google and Baidu, comprehensive statistics of the Internet hot concept are made, including those having the largest annual search, or the largest increase in search volume, or the most frequently mentioned, or the most obvious upward trend. As is shown in the Fig. 1, those concepts are the sample of this thesis.

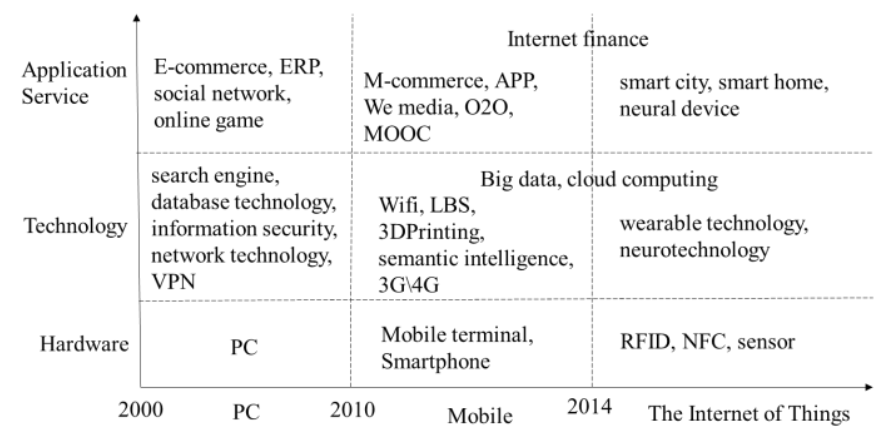

Fig. 1 Internet hot concept since 2000 (part)

From memes' perspective due to the lack of physical boundaries, Internet information spreads faster and more accurately, therefore the cultural establishment of virtual community is narrower, more extreme and more unstable. [12] So the recession rate of various concepts and information's network fame is easily as fast as its growth rate. This thesis will mainly discuss the factors for the Internet hot concept being popular and divide those into three levels: (1) National policies, laws and regulations. The country conducts guidance and takes control in macro-level for a particular industry. Concepts will easily arise and become famous under the stimulation of policy, mainly including the enactment of relevant laws and regulations, speech of leaders and so on. (2) Technology application and business model evolution. Mature technology application and business model are important driving factors for the hot concepts and mature industry. Those mainly include industry trends, technology applications and so on. (3) Needs of personalized information on the Internet. Personalized needs of users play a guiding role for the concepts being popular and the industrial development. Those mainly include the new form of Internet products coming into markets, issue of conceptual related publications.

\section{A. The Enactment of Relevant Laws and Regulations}

In the process of industry development some industrial loopholes will unavoidably exist. Therefore, the enactment of relevant laws and regulations always draws great attention in the public and academia. In the view of E-commerce, Google trends reveal that global attention on the concept of $\mathrm{E}$ commerce is declining year by year since 2004. On the one hand, it shows that people no longer have crush on the concept of E-commerce and calm down gradually. On the other hand, it states that the concept of E-commerce has been formed and the development of industry is mature gradually. The news that the UN treaty was drafted on March 22, 2004 to alleviate global ecommerce development has obtained lots of search and concern. Implementation of Electronic Signature Act on April 1, 2005 is considered to be the first E-commerce legislation in China in the true sense. This triggered a hot discussion in the academic field, from the amount of relevant thesis and literature, and reached a peak, 1248, in 2005.

\section{B. Policies Support by Government and Speech Guide of Leaders}

Under the background of policy, national support for related industries is providing good opportunities for industrial development. Policy-making and relevant comments from leaders cause a sharp rise of the attention of concepts. In March 2014 during the CPPCC and NPC sessions, Premier Li stressed in Government Work Report that the healthy development of Internet finance should be promoted and the concept of 'Internet finance' should be made to enter public view. The exposure of the network financial fraud in 315 CCTV caused wide concern from investors, which even made the attention of 'Internet finance' reach a peak. With the growing maturity of the relevant technologies and models, 'Internet finance' has been transferred from concept hype to commercial application stage.

Another concept is 'smart city', this word originated from the concept of 'smart planet' put forward by IBM in 2008. After the state proclaimed the 'Twelfth Five-Year Plan' in 2010, governments at all levels take 'smart city' as the main development pattern of the next five years. Therefrom the concept of 'smart city' sprung up quietly. Since November 2011, searches for 'smart city' have risen abruptly and continuously. In addition to the communication through forum about the theme of 'smart city' by the relevant industry, more importantly, many governmental organizations began to put this development pattern into practice during this period. The Ministry of Housing and Urban-Rural Development enacted Index System about National Smart City (District, Town) for Pilot in December 2012 and the publication of the national smart city pilot list in February and August 2013, which made the smart city gain unprecedented attention. In December 2013, Premier Li strongly recommended smart city in EUChina Urbanization Partnership Cooperate Forum, which also earned high searches. 


\section{Relevant Industry Trends as well as Discussion and Communication}

The reflection and discussion on industry issues from the industry as well as holding the conferences and activities all promote the rise and development of the popular concept. Having analyzed the search change in the Baidu search index of E-commerce, we found that the attention to E-commerce increased steadily year by year from 2007 to 2014. And every year in late June to early July, it is the highest peak of the year for the searches of E-commerce by the public. The main reason is that the E-commerce scrimmage (several Ecommerce enterprises making online promotion at the same time) happens every year in June. At the same time, the major choice of the college entrance examination, the employment of fresh graduate and other related hot issues all sparked heated discussion.

Another frequently searched concept is 'big data'. Its media attention increased sharply from 2012 and reached the first search extent peak in August 2012. Intel Hadoop released in China on July 21 exerts a role upon promoting the big data concept. Media hype about the 'big data' reached the peak in 2013. The big data business carried out in IBM, Google, BAT (three famous Internet companies in China, Baidu, Alibaba, and Tencent) and other Internet companies caused great attention and boost the spread of the concept of 'big data'. In April 2013, big data industry chain of Zhongguancun (the high-tech industry center of China) begun to take shape and triggered a new round of the focus of netizens' attention. In the same year, Political Bureau of the Central Committee of Chinese invited Li Yanhong (the CEO of Baidu company) to expound the big data in September, and National Bureau of Statistics signed an agreement with Baidu, Alibaba and other companies to jointly build National Bureau of Statistics' big data cooperation platform in November. Those acts further boosted the spread of the big data concept. Internet companies and government decision-making departments make up the two critical forces of communication matrix about the concept of 'big data'. And the news media, as the pioneering in the application of the big data, promote the popularity of the concept in a more intuitive way.

\section{Mature Application of Industry Technology}

Breakthroughs and increasing maturity of the industry technology can make the popular concept land rapidly and step into the stage of steady development. At the same time, the media's less concern and the public acceptance enhancing correspondingly. Concerning the amount of related literature and research focus in academic field, it has risen sharply since 2012 and the related research focus shifted from technologydriven to application-driven. Before 2012, the mainstream of academic research lay in technical problems, such as data storage, system design, calculation method, programming model and so on. 'Large data', 'large data flow' and other similar concepts were used more frequently. But starting in 2012, cloud computing, Hadoop, data mining, Internet of Things and other emerging technologies widen the applied range of the big data. The academia pays more attention to how to transform the big data technology into productivity. With the maturity of technology and the popularity of commercial application, the 'big data' is transferred from the focus of concept hype to the implement of systematic and practical theoretical system.

Since 2014, the concept hype of 'big data' has returned to rationality; popularity of technology hype has fallen dramatically, and the frequency of news report has entered the plateau. In February 2014, the search extent of the 'big data' began to explode and the Spring Festival Gala reports of big data drew public attention on it. In March, the proposals related to the big data were surged, and a good many of media reports caused the public attention on 'big data' to hit a new peak. During the World Cup in June, event prediction or broadcast by big data and other applications were popping up, which made the attention of big data rise steeply in the World Cup carnival. The gradual maturity of technological means and application modes puncture the hype bubble of big data, and the large enterprises also focus on enhancing productivity.

\section{E. New Forms of Internet Products Coming into Market}

Iterative upgrade of technology and popularization of product application make people's social life change radically. New forms of Internet products coming into the market boost the popular concepts' evolution. The development of the Internet finance has gone through several stages, but the concept began to widely circulate in 2013, and the attention reached its peak in 2014, as is shown in Fig. 2.

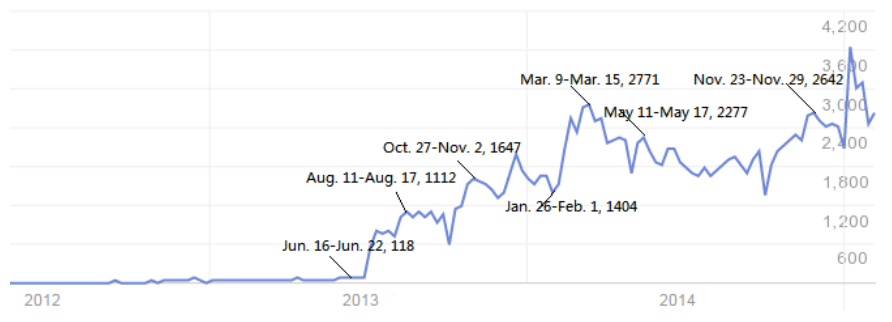

Fig. 2 The Baidu search trends of 'Internet finance' from 2012 to 2014

Viewed from the search extent, June 2013 is the starting point of the explosive growth of the 'Internet finance'. The concept was detonated by the launch of Yu'ebao (a kind of financial product provided by Alibaba) in June 13, 2013. Yu'ebao gave rise to the boom of the Internet financial management and made the concept of 'Internet finance' gradually form. In August 2013, the payment of Wechat came into effect, and followed, many fund companies launched similar financial services. The attention degree of the 'Internet finance' concept reached the first small peak. Beginning in October 2013, various financial products of Baidu appeared on the market in succession. After that, large enterprises, such as NetEase, Suning, Jingdong, launched related financial sales platform one after another. The search frequency of the 'Internet finance' achieved its peak. In 2014, the attention degree of the 'Internet finance' concept was in a new round of rising channel. On January 26, since lucky money of Wechat were online, the attention degree of the 'Internet finance' has 
gone up and reached its peak in mid-March. In addition to the boost from various electronic financial products, lucky money of Wechat being popular overnight also demonstrates the viral marketing magic of the 'Internet finance'. Popularity of various Internet financial products constitutes the communication matrix of the concept of the 'Internet finance'. The value and leading edge of the Internet industry has also been improved.

Another example is wearable devices. It's derived from an innovative technology 'wearable technology' which was put forward by the media lab of the MIT in 1960's. In 1975, the launch of Pulsar calculator watch that undoubtedly created the precedent of wearable device. At the beginning of 2013, Google launched the beta version of Google glasses to some users that made the 'wearable devices', a popular concept from an industry term. At the same time, it also induced discussions about whether the wearable device can be popularized, whether the wearable device violate privacy and other problems. The rise and popularity of wearable devices will bring radical changes in our lives.

\section{F. Issues of the Publications Relevant to the Internet Concept}

Hot selling of the publications relevant to the Internet concept drives it to the peak of public opinion, and activates further analysis of the academic and the industry. Take the book Big Data and the film The Social Network for examples, the 'big data' is one of the typical labels of industry collective hype on technology package. The rise of the concept of the 'big data' in China can be attributed to the publication of Big Data at the end of 2012. Forward-looking views and abundant business application cases in the book quickly attracted the attention from all walks of life in the country. Strongly recommended and frequent quotes by the academia, the industry and the politicians not only put Big Data on the list of bestsellers, but also make the public attention of 'big data' concept shoot up.

E-mail is the starting point of social network, when BBS, Instant Message, blog and other social tools social network applications penetrated into all areas of public social life. Public attention on the concept of 'social network' used to be in a steady state, but reached its first search peak on October 31, 2010 to November 6, 2010 when the film The Social Network was hotly on in China. In addition to the film itself, it also triggered great attention to the concept of 'social network'. Furthermore, before and after the Oscars in 2011, it set off the search on the concept of 'social network' once again. The issue of The Social Network made a substantial rise of the attention on the concept of 'social network' that was used to be stable, while promoting the development of social network applications into maturity.

\section{Conclusion}

Numerous popular concepts that appear in different times reflect the development trends of the Internet, thus quickly becoming the frontier issues of the academia and the industry. On the basis of analyzing the public search attention, the discussion degree, the academic focus, we explore the important factors of the Internet hot concept being popular.

The evolution of the popular concept changes our daily life constantly and always provokes deep thinking for the development status and prospects of related industries by research scholar and industry. Numerous factors influence the Internet concept and make part of them become famous. On the contrary, if it lacks effective stimulation in evolution nodes, the concepts will be ignored and forgotten in the flow of information soon. In the future studies, we will conduct interviews with related industry veterans to dig out more detailed and accurate conclusions.

\section{References}

[1] Shifman L, Thelwall M. "Assessing global diffusion with web memetics: The spread and evolution of a popular joke", Journal of the American society for information science and technology, vol.60, no.12, pp: 2567-2576, 2009.

[2] Schubert, Karen. "Bazaar goes bizarre", USA Today, http://usatoday30.usatoday.com/tech/news/2003-07-28-ebayweirdness_x.htm.

[3] Answers. "Internet meme", http://www.answers.com/topic/internetmeme.

[4] Gu S., Yang J., Liu J. "Problems in the Development of Smart City in China and Their Solution", China Soft Science, vol.27, no.1, pp: 6-12, 2013.

[5] Atzori, L., Iera, A., Morabito, G., Nitti, M. "The Social Internet of Things (SIoT) - When social networks meet the Internet of Things: Concept, architecture and network characterization", Computer Networks, vol.56, no.16, pp: 3594-3608, 2012.

[6] Agrawal D, Bernstein P, Bertino E, et al. "Challenges and opportunities with big data - A community white paper developed by leading researchers across the United States", http://cra.org/ccc/docs/init/bigdatawhitepaper.pdf

[7] Meng X., Ci X. "Big Data Management: Concepts, Techniques and Challenges", Journal of Computer Research and Development, vol.50, no.1, pp: 145-169, 2013.

[8] Uskela, S. "Key concepts for evolution toward beyond 3G networks", Ieee Wireless Communications, vol.10, no.1, pp: 43-48, 2003.

[9] Bari, N., Mani, G., Berkovich, S. "Internet of Things as a Methodological Concept", The Fourth International Conference on Computing for Geospatial Research and Application, Com: Geo, pp: 48-55, 2013

[10] Qiu X. "The Influence and Enlightenment of Yu'ebao on Commercial Banks", New Finance, vol.23, no.9, pp: 50-54, 2013.

[11] Xie P., Zou C. "Study on the Model of Internet Finance", Journal of Financial Research, vol.54, no.12, pp: 11-22, 2012.

[12] Marshall G. "The Internet and memetics", Proceedings of the 15th International Congress of Cybernetics, Namur: Belgium, pp: 443-448, 2005. 